\title{
Oro-facial aspects of leprosy: Report of two cases with literature review
}

\author{
Sujoy Ghosh ${ }^{1}$, Rohit-Bhailal Gadda ${ }^{2}$, Manoj Vengal ${ }^{3}$, Keerthilatha M Pai ${ }^{4}$, Chandrasekharan Balachandran ${ }^{5}$, \\ Raghavendra Rao ${ }^{6}$, Ranjini Kudva ${ }^{7}$
}

\author{
${ }^{1}$ MDS, Assistant Professor, Department of Oral Medicine \& Radiology, Manipal College of Dental Sciences, Manipal, Karna- \\ taka, India \\ ${ }^{2}$ BDS, Post-graduate student, Department of Oral Medicine \& Radiology, Manipal College of Dental Sciences, Manipal, Kar- \\ nataka, India \\ ${ }^{3}$ MDS, Associate Professor, Department of Oral Medicine \& Radiology, Manipal College of Dental Sciences, Manipal, Karna- \\ taka, India \\ ${ }^{4}$ MDS, Professor \& Head, Department of Oral Medicine \& Radiology, Manipal College of Dental Sciences, Manipal, Karnataka, \\ India \\ ${ }^{5}$ MD, Professor \& Head, Department of Dermatology, Kasturba Medical College, Manipal, Karnataka, India \\ ${ }^{6} \mathrm{MD}, \mathrm{DNB}$, Associate Professor, Department of Dermatology, Kasturba Medical College, Manipal, Karnataka, India \\ ${ }^{7}$ MD, Professor, Department of Pathology, Kasturba Medical College, Manipal, Karnataka, India
}

Correspondence:

Department of Oral Medicine \& Radiology

Manipal College of Dental Sciences

Manipal, Karnataka, India

rohitgadda@gmail.com

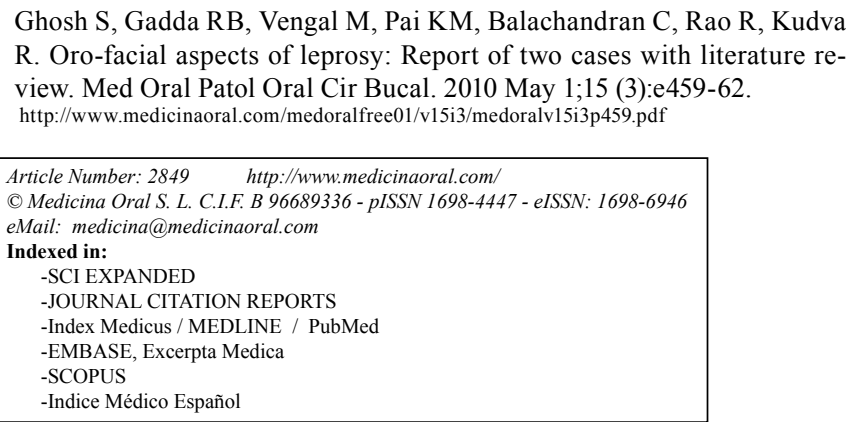

\begin{abstract}
Leprosy is a chronic infectious disease affecting primarily the skin, peripheral nerves, respiratory system and the eyes. Leprosy induces various types of clinical presentation affecting the patient's immune response. Cellmediated immunity is considered to be the crucial defence against the disease and the magnitude of this immunity defines the extent of the disease. The article presents two case reports of manifestations of leprosy in the oro-facial region, with a brief review of various other important oro-facial manifestations of leprosy. The first report deals with granulomatous nodules in the palate while the second report presents bilateral facial palsy in leprosy patients. Both the reports gain importance due to rare oral manifestation in a borderline leprosy patient in the first case, while the second case presents a rare bilateral Bell's sign. The role of the dental profession and especially the Oral Medicine specialist is of great importance in early diagnosis of oral lesions.
\end{abstract}

Key words: Leprosy, oro-facial manifestations, granuloma, facial palsy, bell's sign. 


\section{Introduction}

Leprosy or Hansen's disease is a chronic infectious disease caused by Mycobacterium leprae, affecting primarily the skin, peripheral nerves, respiratory system and the eye. The global prevalence rate is around 1.25 per 10,000 persons (1). Infection with this bacillus induces various types of clinical presentation corresponding to patient's immune response. The two polar ends of the disease spectrum include tuberculoid and lepromatous leprosy. The tuberculoid form represents the strongest response, whereas a relatively anergic state is reflected by the lepromatous form (2). The borderline group represents an intermediary position between these 2 forms and is divided into 3 subgroups: Close to the tuberculoid pole (borderline-tuberculoid); in between the tuberculoid and the lepromatous poles (borderline-borderline); and Close to the lepromatous pole (borderlinelepromatous). Cell mediated immunity is considered as the crucial defense against the disease and magnitude of this immunity defines the extent of the disease (2). Oral mucosal lesions are seen in about $20-60 \%$ cases of lepromatous leprosy, while they are quite rare in tuberculoid and borderline forms. The lesions are proportional to the duration of disease, indicating that these are late manifestations $(3,4)$. The oral lesions are generally asymptomatic and secondary to nasal changes. Peripheral nerves are also major targets of leprosy bacillus. The involvement of the nerves by primary infection and immunologically mediated episodes referred to as leprous reaction result in nerve dysfunction and severe disabilities.

\section{Case Reports}

Following are reports of two cases of leprosy which manifested in oro- facial regions with different presentations representing variations of its forms.

\section{Case 1}

27 year old male patient, who was diagnosed as a case of borderline-borderline leprosy, was referred from department of Dermatology, for evaluation palatal swellings of 15 days duration. He had presented with diminished sensation bilaterally on forearms of two years duration, generalized edema of one month duration and reddish scaly patch bilaterally over legs \& forearms of 20 days duration. There was no history of similar palatal lesions in the family. Patient was not having any deleterious habits.

Oral examination revealed the presence of two papulonodular lesions in the center of hard palate (Fig. 1A), both measuring $1 \mathrm{~cm}$ (approx.) in size, non-tender and soft to firm in consistency. There was no evidence of pus discharge or bleeding from the region. There was no evidence of any dental abnormality except for the presence of a supplementary tooth lingual to the mandibular left premolars. As the palatal lesions could not be attrib-

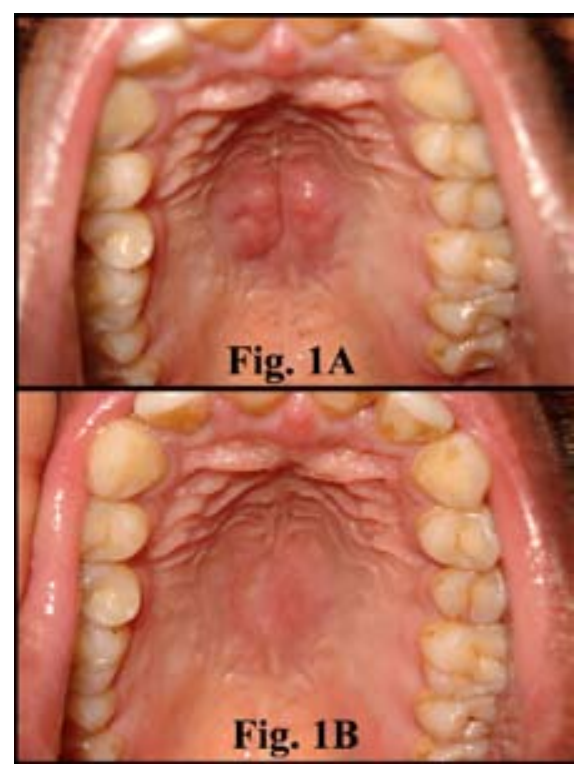

Fig. 1. Papulo-nodular lesions in the center of hard palate (Fig. 1A). Lesion over the palate had completely resolved at follow up visit (Fig. 1B).

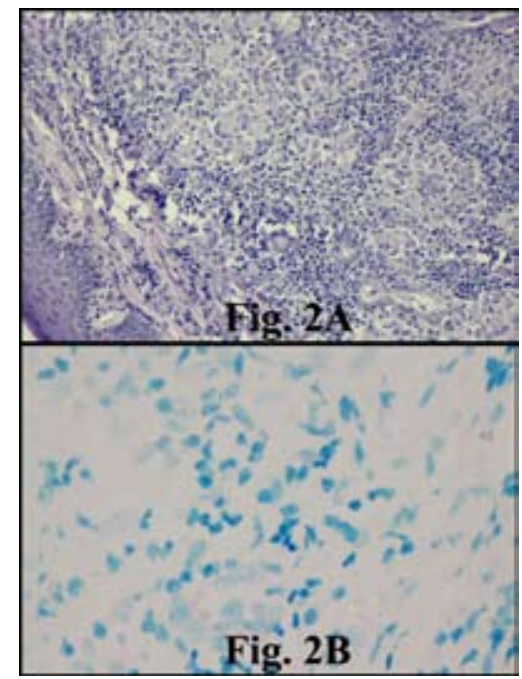

Fig. 2. Histopathological findings of Case 1: Photomicrograph showing aggregate of epithelioid cell granulomas along with scattered Langhans type giant cells and lymphoplasmacytic inflammatory infiltra $\neg$ tion (Hematoxylin and eosin 400X) (Fig. 2A). Occasional bacilli identified using Fite stain (Fig. 2B).

uted to any local factor they were considered to be oral lesions associated with leprosy and biopsied.

The section showed lining of atrophic stratified squamous epithelium with sub-epithelial Grenz zone and a well circumscribed nodular aggregate of epithelioid cell granulomas centered on mucous glands along with scattered Langhans type giant cells and lymphoplasmacytic inflammatory infiltration (Fig. 2A). Occasional bacilli were identified using Fite stain (Fig. 2B). These features 
were suggestive of borderline tuberculoid (BT) leprosy. Patient was started with multidrug therapy for multibacillary leprosy consisting of Dapsone (100 mg once daily), Rifampicin (600 mg once daily), Clofazimine (50 mg/ week) and Prednisolone (10mg thrice daily). On recall visit, lesion over the palate had completely resolved (Fig. 1B). Edema and swelling over the hands and feet had also reduced markedly. Patient is on regular follow up.

Case 2

A 45 year old male was referred from Department of Dermatology for evaluation of oral cavity (Fig. 3A). He was a known case of borderline lepromatous leprosy and was under treatment since 4 months (Multi-drug therapy: Dapsone 100mg once daily, Clofazimine 50 $\mathrm{mg}$ once daily with capsule Rifampicin $600 \mathrm{mg}$ once a month). He demonstrated bilateral Bell's sign and lagophthalmos (Fig. 3B). A detailed assessment of facial

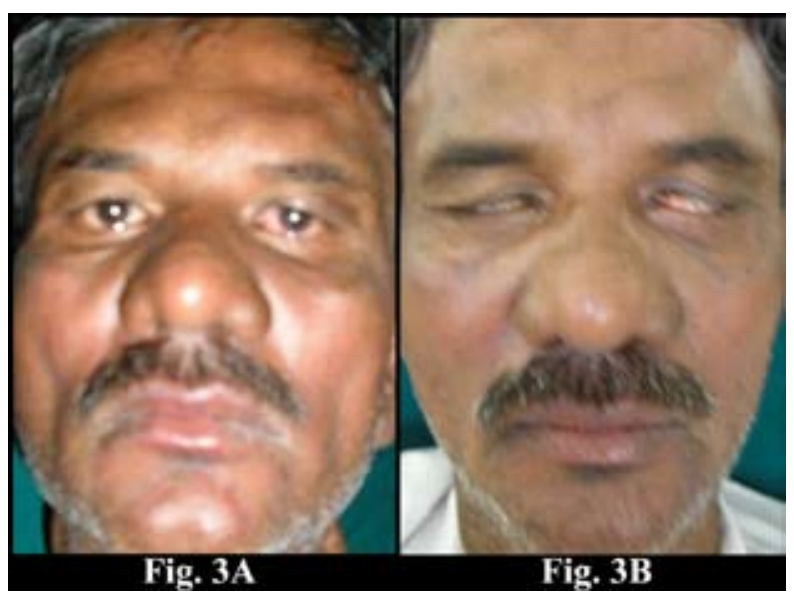

Fig. 3: Facial photograph of Case 2 showing expressionless face (Fig. 3A). Bilateral Bell's sign with lagophthalmos (Fig. 3B) muscles was done by asking the patient to frown and elevate the eyebrows without elevating the head, shut both eyes gently and whistle and inflate the mouth with air. He was unable to do so suggesting weakness of the bilateral facial muscles.

\section{Discussion}

General aspects: The extremely wide spectrum of clini $\neg$ cal manifestations of leprosy may be considered a re $\neg$ flection of different cellular responses to M. leprae. There is a relation between dominant cytokine profiles and clinical presentation of leprosy; interleukin-2 (IL-2) and interferon $\gamma$ markedly dominate in tuberculoid le $\neg$ sions while, IL-4, IL-5 and IL-10 are common in the lepromatous forms of leprosy (5).

Patients with tuberculoid leprosy generally have large macular hypopigmented or erythematous anesthetic le $\neg$ sions which are well defined, often raised margins or occasionally scaly patches. By contrast lepromatous leprosy is usually wide spread and may consist of ery $\neg$ thematous macules, and papules / or nodules. It is re $\neg$ ported that leprosy occurs more frequently in children and young adults and it is more commonly seen in adult males than in females (5).

Oral and facial aspects: Various manifestations of leprosy in oral and maxillofacial region could be summarized in the (Table 1) (3,4, 6-9).

Both cases discussed in this report are significantly special because of the following main reasons: Oral mucosal manifestations are quite common in lepromatous form of leprosy and uncommon in other varieties, whereas our first case was borderline-tuberculoid form.

The second case assumes importance because of the bilateralism in the presentation of facial palsy which is a rare occurrence.

Table 1. Orofacial manifestations of leprosy.

\begin{tabular}{|l|l|}
\hline \multicolumn{1}{|c|}{ Region/part } & \multicolumn{1}{c|}{ Manifestations } \\
\hline $\begin{array}{l}\text { Dermis and cutane- } \\
\text { ous adnexa }\end{array}$ & $\begin{array}{l}\text { Macular/ raised, well defined, hypopigmented, anhydrotic and paresthetic lesions. Leproma- } \\
\text { tous lesions could present as nodular lesions. Advanced stages present as "facies leonine" with } \\
\text { loss of eyebrows and eye lashes. }\end{array}$ \\
\hline $\begin{array}{l}\text { Oral mucosa and } \\
\text { tongue }\end{array}$ & $\begin{array}{l}\text { Mostly seen in lepromatous leprosy, rare in other forms. Early manifestations include granu- } \\
\text { lomatous invasion, proliferation and leproma formation. Late manifestations include ulcer- } \\
\text { ation, scars and soft tissue defect. Lesions in lips may present as macrochelia followed by } \\
\text { microstomia while in the uvula intense fibrosis may be seen. }\end{array}$ \\
\hline Neural lesions & Paralysis of facial and trigeminal nerves usually maxillary division. \\
\hline Skeletal changes & $\begin{array}{l}\text { Destruction of facial cartilages or bones. Primary site being the naso-maxillary complex. } \\
\text { Atrophy of premaxillary region - facies leprosa. Involvement of nasal cartilages and bones - } \\
\text { nasal collapse. }\end{array}$ \\
\hline Dental changes & $\begin{array}{l}\text { Described as odontodysplasia leprosa. Early and severe granulomatous involvement of pre- } \\
\text { maxilla in childhood. Circumferential hypoplasia, shortening of roots, usually involving max- } \\
\text { illary anterior teeth. Long standing lepromatous lesions may show granulomatous invasion of } \\
\text { pulp and pinkish discoloration of crowns. }\end{array}$ \\
\hline
\end{tabular}


Oral lesions of leprosy occur more frequently in areas of the mouth with a lower surface temperature (10). The main oral cavity sites of leprosy include the gingiva in the anterior portion of the maxilla, the hard and soft palate, the uvula, and the tongue (3). The sequence of pathological alterations follow the pattern as described: congestion, infiltration, formation of nodules, possible ulceration, atrophy and fibrosis $(4,9)$. In the first case there was complete healing of the lesions after the commencement of treatment with multiple drug therapy regimens. In advanced leprosy the mouth can acquire the characteristics of a reservoir of bacilli, and thus may act as an important risk factor for transmission of the illness (7).

Unilateral facial paralysis is a relatively common diagnosis with an incidence of 20 to 25 per 100,000 people (11). However, simultaneous bilateral facial palsy (BFP) is rather uncommon and occurs in $0.3 \%$ to $2.0 \%$ of the facial palsy cases (12). Incidence of facial palsy in leprosy has been varying; it ranges from $3 \%$ to $24.59 \%$ (8). The causes of BFP range from congenital dysplasia to tumors, infections and degenerative diseases. The mechanism of nerve damage in leprosy remains diverse and unclear. On lepromatous side of the spectrum, nerves are damaged by direct infiltration by $\mathrm{M}$. leprae. In the tuberculoid type of leprosy, the nerve damage is caused by granulomatous infiltration (13). Facial nerve paralysis is thought to be due to bacterial invasion in the extra-cranial part of facial nerve (14). The main dangers for the eye in leprosy are lagophthalmos, corneal hypoesthesia and iridocyclitis (13).

India accounts for $80 \%$ of the detection of leprosy cases in the world. The annual case detection rate in India is among the highest in the world (53 per 100,000) (1). The rise in multibacillary cases is more in comparison with the paucibacillary cases. Diagnosis of leprosy continues to depend predominantly on clinical criteria, with laboratory findings usually being supplementary in nature. Of the cardinal features of leprosy, only the demonstration of acid-fast bacilli has been dependent upon the laboratory. The method of choice, as propagated by the World Health Organization (WHO), is the slit-skin smear (5). Three major strategic components of leprosy control include: early detection of the disease, adequate treatment and comprehensive care for prevention of disabilities and rehabilitation (1). Oral leprosy lesions are nonspecific in their presentation and are often overlooked by clinicians or misdiagnosed. The role of dental profession and especially the Oral Medicine specialist is of great importance in early diagnosis of oral lesions. A thorough knowledge of this chronic infection is hence necessary to provide optimum level of health care.

\section{References}

1. Sasaki S, Takeshita F, Okuda K, Ishii N. Mycobacterium leprae and leprosy: a compendium. Microbiol Immunol. 2001;45:729-36.

2. De Abreu MA, Alchorne MM, Michalany NS, Weckx LL, Pimentel DR, Hirata CH. The oral mucosa in paucibacillary leprosy: a clinical and histopathological study. Oral Surg Oral Med Oral Pathol Oral Radiol Endod. 2007;103:e48-52.

3. Bucci F Jr, Mesa M, Schwartz RA, McNeil G, Lambert WC. Oral lesions in lepromatous leprosy. J Oral Med. 1987;42:4-6.

4. Girdhar BK, Desikan KV. A clinical study of the mouth in untreated lepromatous patients. Lepr Rev. 1979;50:25-35.

5. Bhattacharya SN, Sehgal VN. Leprosy in India. Clin Dermatol. 1999; $17: 159-70$.

6. Chimenos Küstner E, Pascual Cruz M, Pinol Dansis C, Vinals Iglesias H, Rodríguez de Rivera Campillo ME, López López J. Lepromatous leprosy: a review and case report. Med Oral Patol Oral Cir Bucal. 2006;11:E474-9.

7. Motta AC, Komesu MC, Silva CH, Arruda D, Simão JC, Zenha EM, et al. Leprosy-specific oral lesions: a report of three cases. Med Oral Patol Oral Cir Bucal. 2008;13:E479-82.

8. Lighterman I, Watanabe Y, Hidaka T. Leprosy of the oral cavity and adnexa. Oral Surg Oral Med Oral Pathol. 1962;15:1178-94.

9. Costa A, Nery J, Oliveira M, Cuzzi T, Silva M. Oral lesions in leprosy. Indian J Dermatol Venereol Leprol. 2003;69:381-5.

10. Rendall JR, McDougall AC, Willis LA. Intra-oral temperatures in man with special reference to involvement of the central incisors and premaxillary alveolar process in lepromatous leprosy. Int J Lepr Other Mycobact Dis. 1976;44:462-8.

11. Price T, Fife DG. Bilateral simultaneous facial nerve palsy. J Laryngol Otol. 2002;116:46-8.

12. Stahl N, Ferit T. Recurrent bilateral peripheral facial palsy. J Laryngol Otol. 1989;103:117-9.

13. Lubbers WJ, Schipper A, Hogeweg M, de Soldenhoff R. Paralysis of facial muscles in leprosy patients with lagophthalmos. Int $\mathrm{J}$ Lepr Other Mycobact Dis. 1994;62:220-4.

14. Khan A, Sardana K, Koranne RV, Bhushan P. Bilateral seventh nerve palsy--a manifestation of polyneuritic leprosy. Indian J Lepr. 2005;77:140-7. 